\title{
Prevalence of Metabolic Syndrome and its Determinants in Tirunelveli City Police
}

\author{
Premalatha Ramaswamy ${ }^{1}$, Arun Govindan ${ }^{2}$ \\ ${ }^{1}$ Assistant Professor of Physiology, ${ }^{2}$ Assistant Professor of Diabetology, \\ Government Kilpauk Medical College, Kilpauk, Chennai
}

\begin{abstract}
Introduction: Metabolic syndrome has been reported to be on the rise in general population, more so in personnel involved in occupational stress. Hence the present study is undertaken to find out the prevalence of metabolic syndrome and to determine the factors associated with it among the police personnel in Tirunelveli city.

Method: This is a cross-sectional study in which 133 police personnel working in Tirunelveli city in the age group of 30-58 were included. After getting due permission from the Deputy Commissioner of Police Tirunelveli city, Head of Department of Bio chemistry, Institutional Ethical Committee clearance and oral informed consent from the volunteers, the study was started. The study was conducted during the period of August, 2013. Analysis was done using Chi square test and t test using SPSS software version 16. Results: Among the 133 police personnel examined, 92 of them were identified with metabolic syndrome. Hence, prevalence was found to be $69.1 \%$. Majority of them 26 (28.3\%) fell in the age group of 41 to 45 years. History of Smoking, Hypertension and Diabetes were found to be higher among those with metabolic syndrome $(31.5 \%, 20.7 \%$ and $17.4 \%)$ as compared to those who were not affected $(7.3 \%, 7.8 \%$ and $2.4 \%)$ and they were found to be statistically significant with $P$ values of $0.003,0.007$ and 0.017 respectively. The mean values of Age, BMI, Waist circumference, Systolic BP, Diastolic BP, Mean Arterial BP, Fasting Blood Sugar, Serum Triglycerides and VLDL were significantly higher among those who were having metabolic syndrome as compared to other participants.
\end{abstract}

Keywords: Metabolic Syndrome, Police, Tirunelveli city, Determinants.

\section{Introduction}

Metabolic syndrome, an emerging worldwide problem showing a prevalence of $20-25 \%$ is considered as a risk factor for the cardiovascular diseases and type2 diabetes mellitus. As per WHO estimation, more than 300 million people will suffer from diabetes by the year 2025 , globally and 3 out of 4 of these will be living in developing countries ${ }^{1}$.

\section{Corresponding Author:}

Premalatha Ramaswamy

Assistant Professor of Physiology, Government Kilpauk Medical College, Kilpauk, Chennai
The overall prevalence of metabolic syndrome in India varies between $20-46.3 \%{ }^{2,3,4,5}$. Recently the importance of health status of police personnel has been realized and many studies have been undertaken in India. ${ }^{6,7,8,9}$ In a study among the Chennai City Police, carried out in 2008 by Shabana Tharkar et.al., the prevalence of Metabolic syndrome in Police Personnel when compared to general population was found to be significantly on a higher scale showing the rate to be 57.3 vs $28.2 \%{ }^{9}$

In the modern stressful life style, people are in a rush after money and success and following sedentary life style due to luxury and comfort of the contemporary civilization ${ }^{10}$. The reason for attention towards metabolic syndrome remains simple; as the components of this syndrome are associated with increased morbidity 
and mortality especially cardiovascular diseases in particular $^{11}$.

In the modern society, safety and justice of the public is entrusted with the law enforcement officers and so the police work is considered as one of the highly stressful job at present ${ }^{1}$. Studies have found that the police work being a stressful occupation acts as factor for psychological stress ${ }^{4}$. In the bargain, the health and performance of the police personnel are at risk. It has been reported at present that the police officers suffer increased rates of cardiovascular and metabolic disorders, psychological disturbances etc. more than the general population ${ }^{5}$.

Metabolic syndrome which has been reported to be on the rise in general population ${ }^{6}$, more so in personnel involved in occupational stress ${ }^{13}$. Police personnel are exposed to unhealthy life style circumstantially which predisposes them to the symptoms of metabolic syndrome at an early age. Police personnel, when employed, are medically fit and healthy but in matter of few years most of them suffer from abnormalities of health conditions that culminate in the components of metabolic syndrome.

Hence the present study is undertaken to findout the prevalence of metabolic syndrome and to determine the factors associated with it among the police personnel in Tirunelveli city.

\section{Materials and Method}

This is a cross-sectional study in which 133 police personnel working in Tirunelveli city in the age group of 30-58 years were included. Police personnel below 30 years were excluded from the study. After getting due permission from the Deputy Commissioner of Police, Tirunelveli, Head of Department of Bio chemistry Department, Institutional Ethical Committee clearance and oral informed consent from the volunteers, the study was started. The study was conducted during the period August 2013.

\section{Materials Used:}

1. Proforma - A written proforma cum consent form containing subject details and clinical examination findings

2. Stadiometer - To measure the height

3. Portable weighing machine - To record the weight
4. Sphygmomanometer - To record the blood pressure

5. nVac Tube (serum tube) - Non-Vacuum Blood Collecting tube with clot activator to collect blood (5ml tube)

6. Sterile syringes $-3 \mathrm{ml}$ sterile disposable syringes for drawing venous blood

7. Auto analyzer - Estimation of serum glucose and lipid profile

The individuals included in the study were contacted personally in groups of 25-30 on five different days and the details of study were explained to them. Instructions were given to come prepared with overnight fasting for the investigation to be conducted next day. On the day of examination, the proforma containing the written informed consent was filled up in order to get the data regarding personal details, such as dietary habits, sleep duration, physical activity, history of smoking, alcohol etc. The height was measured using stadiometer and the weight was recorded using standard portable weighing machine. The waist circumference was measured using a non- elastic measuring tape that was kept in the horizontal plane, mid- way between the inferior margin of the ribs and the superior border of the iliac crest, at the level of umbilicus. After an interval of 10 minutes rest, the blood pressure was recorded using Sphygmomanometer by the Standard technique of Auscultatory method.

Under aseptic precautions, $3 \mathrm{ml}$ of blood was drawn from the mid-cubital vein using sterile disposable syringe by a trained paramedical staff. The blood was collected in a sterile serum tube (nVac) which contains clot activator in it. The labeled blood samples were carefully taken to the central laboratory of Tirunelveli Medical College immediately and given for estimation of fasting plasma glucose levels and lipid profile.

The blood investigations were carried out in the Auto analysers in the laboratory.

Plasma glucose was determined using glucose oxidase peroxidase method (Trinder's Method). Total cholesterol and Triglycerides were determined by using standard enzymatic method. HDL-C was measured by direct assay method. VLDL was calculated by dividing Triglycerides by 5 and LDL was calculated by taking the difference of Total Cholesterol and VLDL.

The data including anthropometric measurements, blood pressure and results of bio- chemical parameters 
were tabulated for individual cases in the form of master chart for 133 volunteers included in the study. Based on the criteria for metabolic syndrome as mentioned in the modified National Cholesterol Education ProgramAdult Treatment Panel III (NCEP-ATP III), the individuals suffering from metabolic syndrome were identified.

The criteria for diagnosing metabolic syndrome is the presence of at least three of the following five factors.

1. Blood pressure: $\mathrm{SBP}>130 \mathrm{mmHg} /$ or $\mathrm{DBP}>$ $85 \mathrm{mmHg}$ or previously diagnosed hypertension on treatment

2. Waist Circumference: $>90 \mathrm{~cm}$ in males $\&>80 \mathrm{~cm}$ in females

3. Fasting blood glucose: $>110 \mathrm{mg} / \mathrm{dl}$ or previously diagnosed diabetes on treatment.

4. Triglycerides: $150 \mathrm{mg} / \mathrm{dl}$ or on drug for treatment for elevated triglycerides

5. High density lipoprotein-cholesterol: $<40 \mathrm{mg} / \mathrm{dl}$ in males $\&<50 \mathrm{mg} / \mathrm{dl}$ in females or on drug treatment for low HDL.

Among the 133 police personnel, 92 of them were diagnosed with Metabolic Syndrome.

\section{Results Analysis}

Table 1 shows that about $23.8 \%$ of the respondents were in the age group of 41 to 45 years.
Among the 133 police personnel examined, 92 of them were identified with metabolic syndrome. Hence, prevalence was found to be $69.1 \%$.

Table 1: Age distribution among the total individuals examined $(\mathrm{N}=\mathbf{1 3 3})$

\begin{tabular}{|l|c|c|}
\hline Age (Years) & Number & Percentage \\
\hline $30-35$ & 29 & $21.8 \%$ \\
\hline $36-40$ & 25 & $18.8 \%$ \\
\hline $41-45$ & 31 & $23.8 \%$ \\
\hline $46-50$ & 16 & $12 \%$ \\
\hline $51-55$ & 26 & $19.5 \%$ \\
\hline Above 55 & 06 & $4.5 \%$ \\
\hline
\end{tabular}

Majority of them 26 (28.3\%) fell in the age group of 41 to 45 years (Table 2 ).

Table 2: Age distribution of the individuals identified with metabolic syndrome $(\mathrm{N}=92)$

\begin{tabular}{|l|c|c|}
\hline Age (Years) & Number & Percentage \\
\hline $30-35$ & 12 & $13 \%$ \\
\hline $36-40$ & 15 & $16.3 \%$ \\
\hline $41-45$ & 26 & $28.3 \%$ \\
\hline $46-50$ & 14 & $15.2 \%$ \\
\hline $51-55$ & 20 & $21.7 \%$ \\
\hline Above 55 & 05 & $5.4 \%$ \\
\hline
\end{tabular}

Table 3: Comparison of history of smoking, alcohol, HTN, DM between affected and unaffected individuals

\begin{tabular}{|c|c|c|c|c|c|}
\hline Parameters & & Affected $(\mathrm{N}=92)$ & Not Affected (N=41) & Total $(\mathrm{N}=133)$ & Statistical Inference (P value) \\
\hline \multirow{2}{*}{ Smoking } & Yes & $29(31.5 \%)$ & $3(7.3 \%)$ & $32(24.1 \%)$ & \multirow{2}{*}{0.003} \\
\hline & No & $63(68.5 \%)$ & $38(92.7 \%)$ & $101(75.9 \%)$ & \\
\hline \multirow{2}{*}{ Alcohol } & Yes & $25(27.2 \%)$ & $9(28 \%)$ & $3(25.6 \%)$ & \multirow{2}{*}{0.524} \\
\hline & No & $67(72.8 \%)$ & $32(78 \%)$ & $99(74.4 \%)$ & \\
\hline \multirow{2}{*}{ Hypertension } & Yes & $19(20.7 \%)$ & $1(2.4 \%)$ & $20(15 \%)$ & \multirow{2}{*}{0.007} \\
\hline & No & $73(79.3 \%)$ & $40(97.6 \%)$ & $113(85 \%)$ & \\
\hline \multirow{2}{*}{ Diabetes mellitus } & Yes & $16(17.4 \%)$ & $1(2.4 \%)$ & $17(12.8 \%)$ & \multirow{2}{*}{0.017} \\
\hline & No & $76(82.6 \%)$ & $40(97.6 \%)$ & $116(87.2 \%)$ & \\
\hline
\end{tabular}

Table 3 shows that history of Smoking, hypertension and diabetes were found to be higher among those with metabolic syndrome $(31.5 \%, 20.7 \%$ and $17.4 \%)$ as compared to those who were not affected $(7.3 \%, 78 \%$ and $2.4 \%)$ and they were found to be statistically significant with $P$ values of $0.003,0.007$ and 0.017 respectively. 
Table 4: Comparison of General characteristics between affected and non affected individuals $(\mathbf{N}=133)$

\begin{tabular}{|c|c|c|c|c|c|c|}
\hline \multirow{2}{*}{\multicolumn{2}{|c|}{ Characteristics }} & \multicolumn{2}{|c|}{ Affected $(n=92)$} & \multicolumn{2}{|c|}{ Not Affected $(n=41)$} & \multirow{2}{*}{\begin{tabular}{|c|} 
Statistical Inference \\
P-value
\end{tabular}} \\
\hline & & Mean & SD & Mean & SD & \\
\hline \multicolumn{2}{|l|}{ Age (Years) } & 44.72 & 7.44 & 39.63 & 7.99 & .001 \\
\hline \multicolumn{2}{|l|}{ Height $(\mathrm{cm})$} & 173.36 & 3.910 & 169.73 & 7.56 & - \\
\hline \multicolumn{2}{|l|}{ Weight (kg) } & 83.57 & 9.430 & 73.20 & 8.721 & .000 \\
\hline \multicolumn{2}{|l|}{$\operatorname{BMI}\left(\mathrm{kg} / \mathrm{m}^{2}\right)$} & 27.81 & 2.86 & 25.45 & 2.59 & .000 \\
\hline \multicolumn{2}{|c|}{ Waist circumference $(\mathrm{cm})$} & 98.55 & 7.287 & 89.88 & 7.69 & .000 \\
\hline \multicolumn{2}{|l|}{ Systolic blood pressure } & 130.46 & 17.48 & 116.83 & 10.14 & .000 \\
\hline \multicolumn{2}{|c|}{ Diastolic blood pressure } & 91.59 & 13.65 & 80.44 & 8.86 & .000 \\
\hline \multicolumn{2}{|l|}{ Mean arterial pressure } & 104.76 & 15.19 & 92.56 & 8.70 & .000 \\
\hline \multicolumn{2}{|l|}{ Fasting blood sugar } & 141.73 & 59.27 & 96.49 & 15.04 & .000 \\
\hline \multirow{5}{*}{ Lipid profile (mg/dl) } & T.cho & 168.79 & 27.78 & 161.56 & 29.21 & .175 \\
\hline & TRIG & 220.29 & 91.85 & 129.61 & 54.29 & .000 \\
\hline & LDL & 91.97 & 25.14 & 102.39 & 23.31 & .026 \\
\hline & HDL & 34.03 & 5.31 & 32.9 & 6.47 & .292 \\
\hline & VLDL & 42.66 & 16.95 & 25.85 & 10.89 & .000 \\
\hline
\end{tabular}

T. Cho-Total cholesterol, TRIG- Triglycerides, LDL- Low density Lipoprotein. HDL-High Density Lipoprotein, VLDL-Very low density lipoprotein,

Table 4 shows that the mean values of age, BMI, waist circumference, systolic BP, Diastolic BP, mean arterial BP, fasting BP, serum triglycerides and VLDL were significantly higher among those who were having metabolic syndrome as compared to other participants.

\section{Discussion}

The present study included 133 volunteers of police personnel in Tirunelveli city as an attempt to identify individuals suffering from metabolic syndrome which is found to be on rise in the general population and more so in people under chronic stress because of altered modern lifestyle. When recruited, they are in excellent physical fitness and later on after some years of continuous service they are exposed to occupational stress conditions that can result in alterations in emotional and physical changes.

The study was proceeded with detailed history taking related to occupation, personal and dietary habits in the proforma. Clinical examinations and relevant estimation of physiological parameters such as height, weight, waist circumference, blood pressure and bio chemical investigation that included fasting blood sugar level and lipid profile were taken.
On tabulation of the data collected from the 133 participants in the study, 92 were identified with metabolic syndrome who had criteria as stipulated in modified national cholesterol education programme -adults treatment panel III (NCEP-ATP III). This shows the prevalence rate in this study to be $69.1 \%$. Earlier reports from Chennai study by Shabana Tharkar et.al have mentioned the prevalence rate of metabolic syndrome in police personnel as $57.3 \%(2008)^{9}$. Our study results can therefore be considered to indicate the increasing incidence.

Among the 133 individuals examined, 32 of them gave a positive history of smoking habit and among them 29 were affected with metabolic syndrome, these results coincides with the study of Yusuf et al, 2004 ${ }^{14}$, which says that two third of the risk for cardiovascular diseases comes from smoking. Also study by Joshi P et al, $2007^{15}$ points out that smoking is a major risk factor for early myocardial infarction in South Asians.

The increase in the prevalence rate of metabolic syndrome can be attributed to the chronic stress among police personnel. Chronic stress causes activation of sympathetic nervous system and leads to visceral obesity, insulin resistance, hyper tension, dyslipidemia 
and type 2 diabetes mellitus ${ }^{16,17}$. Also studies show that work stress and sleep disturbance cause hyperglycemia leading to type 2 diabetes mellitus. ${ }^{18,19}$ Studies also show that increased sympathetic activity and decreased parasympathetic activity due to stress is associated with insulin resistance ${ }^{20}$ and visceral adiposity. ${ }^{21}$ Increased activity of both HPA - axis and sympathetic nervous system are being activated in persons with metabolic syndrome which is due to psychosocial factors ${ }^{22}$. Stress also releases cytokines from the visceral adipose tissue $^{23}$. causes low grade inflammation causes insulin resistance. TNF- $\alpha$ impairs insulin signalling ${ }^{24}$ and also impairs capillary recruitment ${ }^{25}$ and also cause increase in Reactive Oxygen Species levels which activates the stress kinase JNK and intum increases IRS-1 serine phosphorylation ${ }^{26}$ and cause insulin resistance through oxidative stress.

Further studies on interventions like Physical fitness schedule, along with stress alleviation techniques and dietary modifications and their effects on metabolic syndrome may be conducted to keep the police personnel physically and mentally healthy.

\section{Conflicts of Interest: Nil}

\section{Ethical Committee Clearance: Obtained}

\section{Source of Funding: Self}

\section{References}

1. Geetha PR, Subbakrishna DK, Channabasavanna SM. Subjective well being among police personnel. Indian J Psychiatry. 1998;40:172-9.

2. Dee Pa M, Farooq S, Datta M, Deepa R, Mohan V. Prevalence of metabolic syndrome using WHO, ATPIII and IDF definitions in Asian Indians: the Chennai Urban Rural Epidemiology Study (CURES-34). Diabetes Metab Res Rev. 2007 Feb: 23(2) :127-34.

3. P Padmavathi, E Sailaja, A Renuka, E Gnana Desigan, K Balu Mahendran. Prevalence of Metabolic Syndrome. international journal of research in pharmacetical and biomedical sciences 08/2013;4.

4. Manopriya Thiruvagounder, Shaheen Khan, Dhastagir Sultan Sheriff. The prevalence of metabolic syndrome in a local population in India. Biochemia Medica 2010;20(2):249-52.

5. Apurva Sawant, Ranjit Mankeshwar, Swarup Shah,
Rani Raghavan, Gargi Dhongde, Himanshu Raje, Shoba D'souza, Aarti Subramanium, Pradnya Dhairyawan, Seema Todur and Tester F. Ashavaid' Prevalence of Metabolic Syndrome in Urban India. Cholesterol. Volume 2011 (2011), Article ID 920983, 7 pages

6. Kaushik Pandit, Soumik Goswami, Sujoy Ghosh, Pradip Mukhopadhyay and Subhankar Chowdhury, Metabolic syndrome in South Asians. Indian J Endocrinol Metab. 2012 Jan-Feb; 16(1): 44-55.

7. Thayyil J, Jayakrishnan TT, Raja M, Cherumanalil JM. Metabolic syndrome and other cardiovascular risk factors among police officers. N Am J Med sci. 2012 Dec;4(12):630-5. doi: 10.4103/19472714.104313.

8. Kumar P, Mallik D, Mulchopadhyay DK, Sinhababu A, Mahapatra BS, Chakrabarti P. Prevalence of diabetes mellitus, impaired fasting glucose, impaired glucose tolerance and its correlates among police personnel in Bankura District of West Bengal. Indian J Public Health. 2013 Jan-Mar;57(1):24-8.

9. Shabana Tharkar, S Kumpatla, P Muthukumaran, Vijay Viswanathan. High prevalence of metabolic syndrome and cardiovascular risk among police personnel compared to general population in India. The Journal of the Association of Physicians of India 11/2008; 56:845-9.

10. Nicoleta Milici, A short history of the metabolic syndrome definitions, Proc. Rom.Acad., series B, 2010,/, P.13-20.

11. Knut Borch-Johnsen Professor, The metabolic syndrome in a global perspective The Public Health impact—secondary publication, Dan Med Bull 2007;54:157-9.

12. Ravneet Kaur, Vamsi K, Chodagiri, Narasimha K.Reddi, A psychological study of stress, personality and coping in police personnel. Indian Journal opf psychological medicine, Apr- Jun, 2013, Vol.35, Issue 2.

13. Atanu saha, Subhashis sahu and Goutam paul, Evaluation of cardio vascular risk factor in police officers. International Journal of pharma and bio sciences, Vol. 1/issue -4/Oct- Dec. 2010.

14. Yusuf, S.et al ., Effect of potentially modifiable risk factors asso-ciated with myocardial infarction in 52 countries (the INTERHEART study): case-control study. Lancet, 2004,364, 937-952. 
15. Joshi, P.et al ., Risk factors for early myocardial infarction infarction in South Asians compared with individuals in other countries. JAMA, 2007, 297, 286-294.

16. Buren, J., Eriksson, J.W., 2005. Is insulin resistance caused by defects in insulin'starget cells or by a stressed mind? Diabetes Metab. Res. Rev. 21, 487494.

17. Shabana Tharkar, S Kumpatla, P Muthukumaran, Vijay Viswanathan. High prevalence of metabolic syndrome and cardiovascular risk among police personnel compared to general population in India. The Journal of the Association of Physicians of India 11/2008; 56:845-9.

18. Hall MH, Muldoon MF, Jennings JR, Buysse DJ, Flory JD, Manuck SB. Self-reported sleep duration is associated with the metabolic syndrome in midlife adults. Sleep 2008; $31: 635-43$.

19. Mikaela Sjostrand ..a, b, Jan W. Erikssona, $\mathrm{b},{ }^{*}$ Neuroendocrine mechanisms in insulin resistance.. Molecular and Cellular Endocrinology 297 (2009) 104-111.

20. Buren, J., Eriksson, J.W., 2005. Is insulin resistance caused by defects in insulin'starget cells or by a stressed mind? Diabetes Metab. Res. Rev. 21, $487-$ 494.

21. Lönnroth $\mathrm{P}$, Smith U. Intermediary metabolism with an emphasis on lipid metabolism, adipose tissue and fat cell metabolism-a review. In: Björntorp P, Brodoff B, editors. Obesity: Lipincott Press; Philadelphia. p. 3-14.

22. Rytka JM, Wueest S, Schoenle EJ, Konrad D. The portal theory supported by venous drainageselective fat transplantation. Diabetes. 2011 Jan;60(1):56-63.

23. Arner P. Regulation of lipolysis in fat cells. Diabetes Rev. 1996;4:450-63.

24. Nakada MT, Stadel JM, Poksay KS, Crooke ST. Glucocorticoid regulation of beta adrenergic receptors in 3T3-L1 preadipocytes. Mol Pharmacol. 1987 Apr; 31 (14) :377-84.

25. Björntorp P. Adipose tissue distribution and function. Int J Obes. 1991;15:67-81

26. Kreier, F., Fliers, E., Voshol, P.J., Van Eden, C.G., et al. 2002 Selective asympathetic innervation of subcutaneous and intr abdominal fat - functional implications. J . Clin. Invest. 110, 1243-1250 